Nrmmo-Smith, R. H. \& Brown, D. J. (1953). J. gen. Microbiol. 9, 536-544.

\title{
Some Effects of 2-Deaminopteroylglutamic Acid upon Bacterial Growth
}

\author{
BY R. H. NIMMO-SMITH \\ Microbiology Unit, Department of Biochemistry, Oxford \\ AND D. J. BROWN \\ Department of Medical Chemistry, Australian National University
}

\begin{abstract}
SUMMARY: Four analogues of pteroic acid and one of pteroylglutamic acid were tested for their ability to stimulate growth of Streptococcus faecalis $\mathbf{R}$ in the absence of pteroic acid or to inhibit growth in its presence. The four analogues of pteroic acid were inactive in either respect, but 2-deaminopteroylglutamic acid was inhibitory. Inhibition of the organism was most marked in the presence of pteroic acid, and became relatively more efficient as the concentrations of inhibitor and growth factor were increased. Inhibition was much less marked in the presence of rhizopterin or Leucovorin, the relative efficiency decreasing in comparable conditions. Pteroylglutamic acid had an intermediate position and showed a competitive relationship.

Lactobacillus casei was similarly inhibited when growth was supported by either pteroylglutamic acid or Leucovorin, but was less pronounced in the presence of the latter. On the other hand, the analogue could substitute for pteroylglutamic acid in stimulating the suboptimal growth supported by a mixture of thymine and a purine in the absence of added folic acid.

Several other organisms whose growth is independent of exogenous folic acid were unaffected by the analogue.
\end{abstract}

The synthesis of analogues and derivatives of pteroic acid and pteroylglutamic acid has been undertaken in several laboratories in order to throw light upon the functioning of the metabolically important folic acid group of substances (e.g. see reviews by Jukes, Franklin \& Stokstad, 1950; Woolley, 1952). The synthesis of 4-hydroxy-6-methylpteridine (Albert, Brown \& Cheeseman, 1952) made it possible for the first time to prepare analogues which lack the amino-group in the 2-position. Five compounds of this type have been synthesized (Brown, 1953), and their structures are indicated in Fig. 1.

\section{METHODS}

Organisms

Streptococcus faecalis $\mathbf{R}$ (American Type Culture Collection, ATCC no. 8043) was maintained by stab subculture in medium $\mathbf{A}$ at $37^{\circ}$.

Lactobacillus casei (ATCC No. 7469) was similarly maintained in medium B1.

\section{Media}

Medium A. For each $100 \mathrm{ml}$.: Marmite, 1 g.; glucose, 0.5 g.; sodium acetate trihydrate, $1 \mathrm{~g}$.; agar, $1 \cdot 5 \mathrm{~g}$; $\mathrm{pH}$ adjusted to $6 \cdot 7-6 \cdot 9$.

Medium B1. For each $100 \mathrm{ml}$. : Tryptose (Difco), 1 g.; yeast extract (Difco), 0.2 g.; glucose, 1 g.; $\mathrm{K}_{2} \mathrm{HPO}_{4}$, 0.5 g.; liver extract (Oxoid, $16 \% \mathrm{w} / \mathrm{v}$ ), $10 \mathrm{ml}$.; 
$\mathrm{MgSO}_{4} .7 \mathrm{H}_{2} \mathrm{O}, 20 \mathrm{mg}$; $\mathrm{FeSO}_{4} .7 \mathrm{H}_{2} \mathrm{O}, 1 \mathrm{mg}$; $\mathrm{MnSO}_{4} \cdot 4 \mathrm{H}_{2} \mathrm{O}, 1 \mathrm{mg} ; \mathrm{CaCO}_{3}$, $1.5 \mathrm{~g}$.; agar, $1.5 \mathrm{~g}$.

Medium B2. As medium $\mathrm{B1}$ but without $\mathrm{CaCO}_{3}$ and agar; $\mathrm{pH}$ 6.7-6.9.

Medium C. This was the medium of Rabinowitz \& Snell (1947) with DL-cysteine (200 mg./l.) instead of L-cysteine, with pyridoxin added at $1 \mathrm{mg} . / 1$. and with folic acid and $p$-aminobenzoic acid left out.

Medium D. The culture medium for $L$. casei was that modification of the Roberts \& Snell (1946) medium previously described (Nimmo-Smith, Lascelles \& Woods, 1948).<smiles></smiles>

Fig. 1. The five compounds investigated were: 6-anilinomethyl-4-hydroxypteridine $(\mathrm{R}=-\mathrm{H})$; 6-p-anisidinomethyl-4-hydroxypteridine $\left(\mathrm{R}=-\mathrm{OCH}_{8}\right)$; 4-hydroxy-6-p-sulphanilinomethylpteridine $\left(\mathrm{R}=-\mathrm{SO}_{\mathbf{3}} \mathrm{H}\right)$; 6-p-carboxyanilinomethyl-4-hydroxypteridine $(R=C O O H)$ and 2-deaminopteroylglutamic acid

$$
\left[\mathrm{R}=-\mathrm{CONH} . \mathrm{CH}(\mathrm{COOH}) \cdot\left(\mathrm{CH}_{2}\right)_{2} \cdot \mathrm{COOH}\right] \text {. }
$$

\section{Materials}

Pteroic acid, pteroylglutamic acid and Leucovorin (5-formyl-5 : 6 : 7 : 8tetrahydropteroyl-L-glutamic acid; 'folinic acid') were synthetic samples generously supplied by Lederle Laboratories Division. Rhizopterin ( $\mathbf{N}^{10}$ formylpteroic acid) was kindly given by the Merck Co., Inc. Stock solutions of each at $10^{-3} \mathrm{M}$ in $10^{-2} \mathrm{M}-\mathrm{NaHCO}_{3}$ were stored in the ice-chest and diluted when needed.

Stock solutions $\left(10^{-3} \mathrm{M}\right.$ in sterile $\left.2 \times 10^{-2} \mathrm{~N}-\mathrm{NaOH}\right)$ of the five analogue compounds were similarly stored.

\section{Methods of cultivation}

The same general precautions were observed as in conducting folic acid assays (Nimmo-Smith, Lascelles \& Woods 1948). Samples of the media (at $70 \%$ of final volume) were distributed in $5 \times \frac{5}{8}$ in. hard-glass test-tubes. Suitable additions of diluted growth factor were made and, where necessary, distilled water was added so that subsequent additions of analogue solution and inoculum brought the contents of each tube to the same final volume.

The tubes were autoclaved for $10 \mathrm{~min}$. at $10 \mathrm{lb} . / \mathrm{sq}$.in. This treatment, at pH 6.8, causes no detectable destruction of even the relatively unstable Leucovorin (unpublished observation by Dr June Lascelles). After autoclaving, different concentrations of the analogues to be tested were added and the tubes inoculated.

Strep. faecalis was grown for $22-24 \mathrm{hr}$, at $37^{\circ}$ in a final volume of $5 \cdot 0 \mathrm{ml}$. medium $\mathrm{C}$ and an atmosphere of air. The inoculum was prepared by growing the organism for $18 \mathrm{hr}$. in medium $\mathrm{B2}$ and diluting the culture 1/100 in sterile water. To each tube $0.5 \mathrm{ml}$. of the dilute suspension was added.

$L$. casei was grown for $24-26 \mathrm{hr}$. at $37^{\circ}$ in a final volume of $2.0 \mathrm{ml}$. of medium $\mathrm{D}$ and an atmosphere $5 \% \mathrm{CO}_{2}+95 \% \mathrm{H}_{2}$ (Nimmo-Smith et al. 1948). 
The inoculum was $0.2 \mathrm{ml}$. of a $1 / 100$ dilution in water of a $24 \mathrm{hr}$. culture of the organism in medium $D$ supplemented with $1.5 \times 10^{-8} \mathrm{M}$-pteroylglutamic acid. This had been inoculated with about $0.02 \mathrm{ml}$. of a $16 \mathrm{hr}$. culture in medium B2, inoculated in turn from a fresh $24 \mathrm{hr}$. stab culture in medium B1.

In both cases growth was assessed with a portable colorimeter (Evans Electroselenium, Ltd.), uninoculated medium being used to adjust to zero the reading on the instrument scale. A calibration of dry weight against colorimeter reading was made for each organism and the relationship shown to be linear within the range encountered. Half-maximal growth of Strep. faecalis in our conditions corresponded to an instrument reading of $14(0.69 \mathrm{mg}$. dry wt. $/ \mathrm{ml}$.) and of $L$. casei to a reading of $19(0.65 \mathrm{mg}$. dry wt./ml.).

In the quantitative experiments growth determined in this way was plotted against the logarithm of the concentration of either growth factor or analogue, whichever had been varied. For comparative purposes the molar ratio between analogue and growth factor obtaining at the point of half-maximal growth (or half-maximal inhibition) was used. In most cases serial 1/5 dilutions of growth factor were added to groups of tubes. Within each group the concentration of analogue was fixed, but varied by a factor of 5 from one group to the next. Less commonly the analogue was similarly titrated in the presence of fixed concentrations of the growth factor.

As a first step the five compounds were 'screened' with Strep. faecalis $\mathbf{R}$ in media (a) without folic acid, and $(b)$ containing a suboptimal concentration $\left(8.3 \times 10^{-8} \mathrm{M}\right)$ of pteroic acid. This technique allows the detection of compounds which can (i) replace folic acid, (ii) stimulate growth in the presence of low concentrations of folic acid or which are (iii) inhibitory.

\section{RESULTS}

Tested over a concentration range from $10^{-7}$ up to $10^{-4} \mathrm{M}$ none of the compounds stimulated growth either on its own or in the presence of suboptimal pteroic acid. However, 2-deaminopteroylglutamic acid showed an interesting type of inhibition; experiments were carried out to determine the behaviour of this compound; the other four were not further investigated.

\section{Effects of 2-deaminopteroylglutamic acid}

Effect on growth of Strep. faecalis $\boldsymbol{R}$. When pteroic acid was acting as source of folic acid the analogue showed itself to be a rather efficient inhibitor. The analogue/growth factor relationship was not a strictly competitive one, since the relative efficiency of the inhibitor increased markedly as the concentration of both was increased. This was shown by the amount of 2-deaminopteroylglutamic acid which had to be added to produce half-maximal inhibition in the presence of different concentrations of pteroic acid (Table 1). In Fig. 2 the logarithm of the molar ratio at half-maximal inhibition has been plotted against the logarithm of the analogue concentration. The position was further complicated by the fact that pterioc acid above about $8.3 \times 10^{-6} \mathrm{M}$ was itself slightly inhibitory. 
In contrast, growth of the organism supported by rhizopterin was much less readily inhibited by the analogue, and the relative efficiency of the latter declined as concentrations were increased. When the concentration of the analogue was increased 25 -fold the analogue : growth factor ratio at the halfmaximal point rose by a factor of about 5 (Table 1 ).

Table 1. Relationship between concentrations of 2-deaminopteroylglytamic acid and of various growth factors at half-maximal growth of Streptococcus faecalis $\boldsymbol{R}$

$P_{t}=$ pteroic acid; $R P t .=$ rhizopterin; $P t G .=$ pteroylglutamic acid; $L V .=$ Leucovorin;

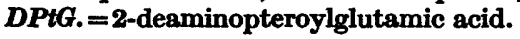

\begin{tabular}{|c|c|c|}
\hline \multicolumn{2}{|c|}{ Concentrations } & \multirow[b]{2}{*}{$\begin{array}{c}\text { Ratio } \\
a: b\end{array}$} \\
\hline $\begin{array}{c}\underset{a}{D P t G .} \\
\left(\times 10^{-5} \mathrm{M}\right)\end{array}$ & $\begin{array}{c}b \\
\text { Growth-factor } \\
\left(\times 10^{-10} \mathrm{M}\right)\end{array}$ & \\
\hline $\mathbf{0}$ & $\begin{array}{l}\text { Pt. } \\
090\end{array}$ & - \\
\hline $\mathbf{3 \cdot 0 5}$ & 1,000 & 305 \\
\hline $6 \cdot 35$ & $\mathbf{3 , 3 0 0}$ & 190 \\
\hline $10 \cdot 0$ & 10,000 & 100 \\
\hline $10 \cdot 9$ & $\mathbf{3 3 , 0 0 0}$ & 33 \\
\hline & RPt. & \\
\hline $\mathbf{0}$ & 15 & - \\
\hline 4 & 15 & 26,700 \\
\hline 20 & 20 & 100,000 \\
\hline 100 & 71 & 141,000 \\
\hline & PtG. & \\
\hline $\mathbf{0}$ & 14 & - \\
\hline 4 & 40 & 10,000 \\
\hline 20 & 170 & 11,800 \\
\hline 100 & 865 & 11,600 \\
\hline & $L V$. & \\
\hline $\mathbf{0}$ & 14 & - \\
\hline 4 & 19 & 21,000 \\
\hline 20 & 45 & 44,000 \\
\hline 100 & 110 & 90,000 \\
\hline
\end{tabular}

When pteroylglutamic acid was acting as source of folic acid, 2-deaminopteroylglutamic acid produced half-maximal inhibition at a molar ratio of about $1: 10,000$. The relationship between the two, at least over a 50 -fold range of concentration, appeared to be a competitive one (Table 1 ).

Behaviour of 2-deaminopteroylglutamic acid in the presence of Leucovorin was very similar to that in the presence of rhizopterin. A 25-fold increase in concentration of the analogue was associated with roughly a five-fold increase in the analogue : growth factor ratio (Table 1).

Synthetic Leucovorin is a mixture of the $+\mathrm{L}$ and $-\mathrm{L}$ isomers and is approximately $50 \%$ as active for Strep. faecalis $\mathbf{R}$ as is the $-\mathrm{L}$ isomer (Cosulich, Smith \& Broquist, 1952), and less active than the natural material for this organism also (Sauberlich, 1952). On the basis that probably only the $l \mathrm{~L}$ isomer is available, concentrations of Leucovorin in Tables 1 and 2 are expressed in terms of this isomer only. 
A medium in which thymine and a purine take the place of folic acid will support adequately the growth of Strep. faecalis $\mathbf{R}$ (Stokes, 1944). In these

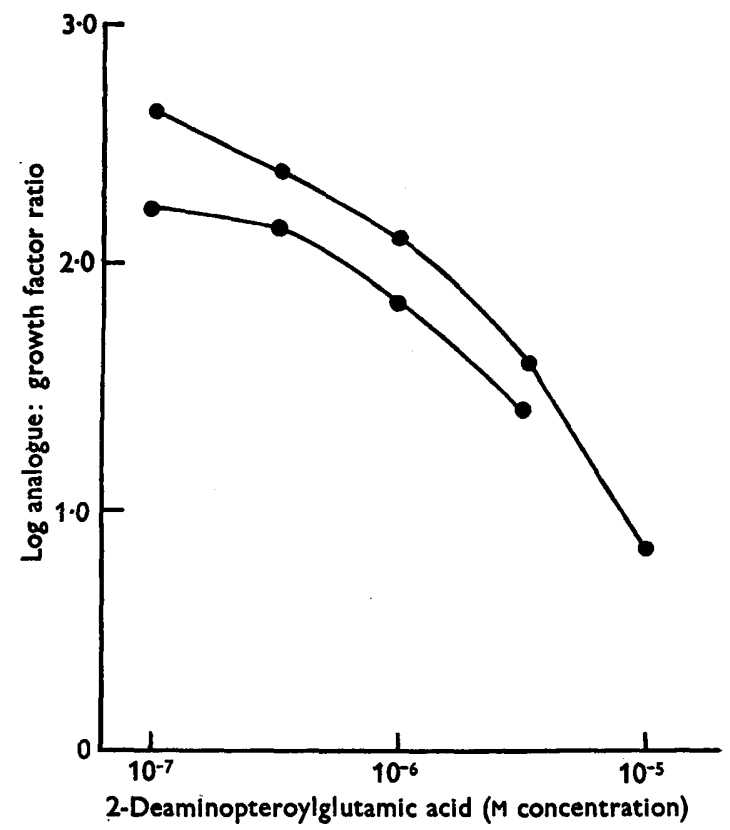

Fig. 2. Relationship between the 2-deaminopteroylglutamic acid : pteroic acid ratio at half-maximal inhibition of Strep. faecalis $\mathbf{R}$ and the absolute concentration of the analogue (two separate experiments).

Table 2. Relationships between concentrations of 2-deaminopteroylglutamic acid and of growth factor at half-maximal growth of Lactobacillus casei

Symbols (DPtG., etc.) have same significance as in Table 1.

\begin{tabular}{|c|c|c|}
\hline \multicolumn{2}{|c|}{ Concentration } & \multirow[b]{2}{*}{$\begin{array}{c}\text { Ratio } \\
a: b\end{array}$} \\
\hline $\begin{array}{c}a \\
D P t G . \\
\left(\times 10^{-5} \mathrm{M}\right)\end{array}$ & $\begin{array}{c}b \\
\text { Growth-factor } \\
\left(\times 10^{-10} \mathrm{M}\right)\end{array}$ & \\
\hline & PtG. & \\
\hline o & 7 & - \\
\hline 4 & 24 & 16,700 \\
\hline 20 & 44 & $\mathbf{4 5 , 5 0 0}$ \\
\hline 100 & 144 & 69,000 \\
\hline & $L V$. & \\
\hline o & 4.8 & - \\
\hline 4 & $6 \cdot 2$ & 64,000 \\
\hline 20 & $11 \cdot 5$ & 174,000 \\
\hline 100 & 39 & 255,000 \\
\hline
\end{tabular}

conditions, with both thymine and hypoxanthine present at a concentration of $10^{-4} \mathrm{M}, 2$-deaminopteroylglutamic acid, tested over the range $10^{-7}$ up to $10^{-3} \mathbf{M}$, was completely without effect upon growth. 
Effect on growth of L. casei. Neither pteroic acid nor rhizopterin support the growth of this organism. 2-Deaminopteroylglutamic acid was inhibitory when growth of this organism was supported by pteroylglutamic acid, halfmaximal inhibition being reached when the concentration of analogue was 1 to $7 \times 10^{4}$ times that of the growth factor.

There is some suggestion of a competitive relationship between the two but, owing to the relatively low activity and solubility of the analogue, it was not possible to test it over an adequate range of concentration. From Table 2 it can be seen that, although the concentration of 2-deaminopteroylglutamic acid was increased 25 -fold the concentration of pteroylglutamic acid had only to be increased fivefold to obtain the same amount of growth.

Growth supported by Leucovorin was more resistant to inhibition (Table 2) than growth in presence of pteroylglutamic acid. Nevertheless, the progressive increase in ratio between analogue and growth factor was precisely the same in each case.

A mixture of thymine and a purine supports also the growth of $L$. casei in the absence of added folic acid. In confirmation of other workers (e.g. Stokes, 1944; Krueger \& Peterson, 1945) we found that growth in these conditions, as measured turbidimetrically, was consistently about half as good as with pteroylglutamic acid. Supplementation with a relatively low concentration of the latter, however, stimulated maximal growth.

Surprisingly, 2-deaminopteroylglutamic acid possesses a similar stimulatory activity. To obtain an increase of $50 \%$ above the basal growth, it must be present at a concentration about 100 times that of the concentration of pteroylglutamic acid needed to produce the same effect (Fig. 3). 2-Deaminopteroylglutamic acid produced its maximum growth stimulatory effect at about $10^{-6} \mathrm{M}$, and stimulated growth which was always slightly suboptimal; it had no further effect on being increased to $10^{-3} \mathrm{M}$.

Effect on growth of other organisms. In addition to the above two organisms which required folic acid as nutrient the analogue was tested for its effect upon the growth of four organisms whose growth in a defined medium is independent of an exogenous supply of folic acid, namely, Bacterium coli, Lactobacillus arabinosus 17-5, L. plantarum $10 \mathrm{~S}$ and Schizosaccharomyces octosporus. Even at $10^{-3} \mathrm{M}$ neither stimulation nor inhibition of growth of any of these organisms was induced by the analogue.

\section{DISCUSSION}

The results show that 2-deaminopteroylglutamic acid is a compound which can interfere with the metabolism of folic acid in two organisms which require this vitamin as a nutrient for growth. It is interesting to note, in the case of Strep. faecalis, how strikingly the relationship between analogue and growth factor alters with the nature of the latter. With pteroic acid a 3-5-fold increase in the concentration of the analogue demands a 33-fold increase in growth factor concentration. Yet a 25 -fold increase of analogue requires only a fivefold increase of rhizopterin to produce the same amount of growth. Both relationships are clearly not competitive, but deviate in opposite directions. 
The relationship between the analogue and pteroic acid is similar to that between 4-aminopteroylglutamic acid and pteroylglutamic acid with this same organism. Oleson, Hutchings \& SubbaRow (1948) found that a ninefold increase in concentration of inhibitor required a 100-fold rise in pteroylglutamic acid concentration to maintain half-maximal growth.

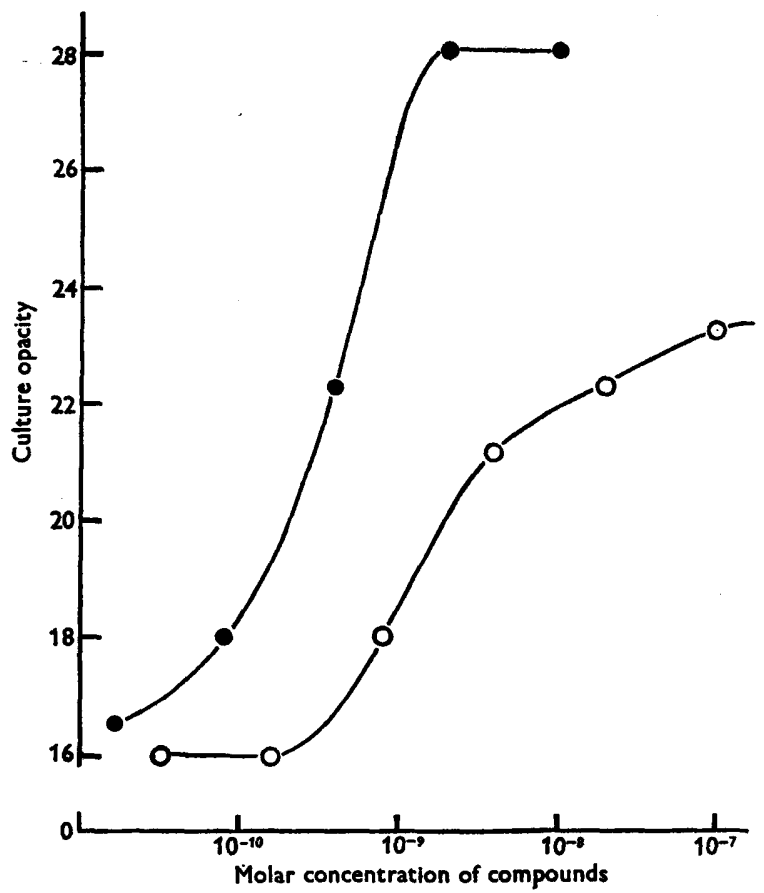

Fig. 8. Stimulation by pteroylglutamic acid $(O)$ and by 2-deaminopteroylglutam.c acid (O) of the suboptimal growth of $L$. casei supported by a mixture of thymine and hypoxanthine.

With Strep. faecalis the relationship between 2-deaminopteroylglutamic acid and pteroylglutamic acid, on the other hand, appears to be a competitive one. In the same test conditions pteroylaspartic acid (Hutchings et al. 1947) and several inhibitory pterins (Daniel, Norris, Scott \& Heuser, 1947) showed a competitive relationship.

For the type of relationship of the analogue with rhizopterin and Leucovorin in Strep. faecalis, and with pteroylglutamic acid and Leucovorin in $\boldsymbol{L}$. casei, no parallel can be found amongst the other reported analogues of folic acid. On the other hand, inhibition of growth of Strep. faecalis by 7 -methylpteroylglutamic acid is overcome less efficiently by pteroylglutamic acid than by rhizopterin (Gordon, Ravel, Eakin \& Shive, 1948). Similarly, natural Leuconostoc citrovorum factor overcomes the toxicity of 4-aminopteroylglutamic acid in the rat but pteroylglutamic acid does not (Nichol \& Welch, 1950). 
We can offer as yet no acceptable explanation for the stimulation of the growth of $\boldsymbol{L}$. casei by 2-deaminopteroylglutamic acid in the medium which contained purine and thymine in place of folic acid. Two possibilities might be considered. The first is that $L$. casei is capable of aminating the compound and that this is a slow reaction which only proceeds at a significant rate when the population is large. It might be achieved where there is considerable growth independent of folic acid, but not where there is a small initial population and where the ratio between analogue and growth factor is an inhibitory one. The second and more remote possibility is that the thymine-purine medium contains the end-products of all but one of the reactions for which folic acid is required, and that this hypothetical reaction can be catalysed by a form of folic acid which lacks the 2-amino group. One of the difficulties of accepting this suggestion is that the organism grows in these conditions at an apparently maximal rate (although to a submaximal density) without the addition of folic acid. The last postulated function cannot therefore be regarded as essential, or else suboptimal traces of folic acid are $(a)$ present in the medium, or are (b) synthesized by $L$. casei (cf. Rogers \& Shive, 1948). All that can be said with certainty, however, is that the real explanation can only be found after further experiments.

We wish to record our gratitude to Prof. A. Albert for the interest he has shown in this work, to Dr D. D. Woods for his encouragement and many helpful suggestions, and to Mrs Doreen Wakelin for valuable technical assistance.

\section{REFERENCES}

Albert, A., Brown, D. J. \& Chezseman, G. (1952). Pteridine studies. Part III. The solubility and the stability to hydrolysis of pteridines. J. chem. Soc. p. 4219.

Brown, D. J. (1958). Some pteridines related to folic acid. Part I. 2-Deaminoanalogues. J. chem. Soc. p. 1644 .

Cosulich, D. B., Smith, J. M. \& Broquist, H. P. (1952). Diastereoisomers of leucovorin. J. Amer. chem. Soc., 74, 4215.

Daniel, L. J., Nornis, L. C., Scott, M. L. \& Heuser, G. F. (1947). Growth inhibition of bacteria by synthetic pterins. Studies with Streptococcus faecalis, Lactobacillus casei and Lactobacillus arabinosus. J. biol. Chem. 169, 689.

.Gordon, M., Ravel, J. M., Eakin, R. E. \& Shrve, W. (1948). Formylfolic acid, a functional derivative of folic acid. J. Amer. chem. Soc. 70, 878.

Hutchinge, B. L., Mowat, J. H., Oleson, J. J., Storstad, E. L. R., Boothe, J. H., Waluer, C. W., Angier, R. B., Semb, J. \& Subbarow, Y. (1947). Pteroylaspartic acid, an antagonist for pteroylglutamic acid. J. biol. Chem. 170, 323.

Jukres, T. H., Frankinv, A. L. \& Stokstad, E. L. R. (1950). Pteroylglutamic acid antagonists. Ann. N.Y. Acad. Sci. 52, 1336.

Krueger, K. \& Peterson, W. H. (1945). The response of Lactobacillus casei and Streptococcus faecalis to vitamin $B_{6}$ and thymine. J. biol. Chem. 158, 145.

Nichol, C. A. \& Wexch, A. D. (1950). On the mechanism of action of aminopterin. Proc. Soc. exp. Biol., N.Y. 74, 403.

Nmmo-SmTth, R. H., Lascelles, J. \& Woods, D. D. (1948). The synthesis of 'folic acid' by Streptobacterium plantarum and its inhibition by sulphonamides. Brit. J. exp. Path. 29, 264.

Ourson, J. J., Hutchings, B. L. \& SubbaRow, Y. (1948). Studies on the inhibitory nature of 4-aminopteroylglutamic acid. J. biol. Chem. 175, 359. 
Rabinowitz, J. C. \& SNell, E. E. (1947). The vitamin $B_{6}$ group. XI. An improved method for assay of vitamin $B_{6}$ with Streptococcus faecalis. J. biol. Chem. 169, 631.

Roberts, E. C. \& Snext, E. E. (1946). An improved medium for microbiological assays with Lactobacillus casei. J. biol. Chem. 163, 499.

Rogers, L. L. \& Shive, W. (1948). Biochemical transformations as determined by competitive analogue-metabolite growth inhibitions. VII. Relationship of purines and thymine to folic acid. J. biol. Chem. 172, 751.

SaUberlich, H. E. (1952). Comparative studies with the natural and synthetic citrovorum factor. J. biol. Chem. 195, 337.

STOKEs, J. L. (1944). Substitution of thymine for 'folic acid' in the nutrition of lactic acid bacteria. J. Bact. 48, 201.

Wooutey, D. W. (1952). A study of Antimetabolites. London: Chapman and Hall Ltd.

(Received 22 June 1953) 